\title{
MRI signal distribution within the intervertebral disc as a biomarker of adolescent idiopathic scoliosis and spondylolisthesis
}

\author{
Julien Gervais ${ }^{1,2}$, Delphine Périé ${ }^{1,2^{*}}$, Stefan Parent ${ }^{2}$, Hubert Labelle ${ }^{2}$ and Carl-Eric Aubin ${ }^{1,2}$
}

\begin{abstract}
Background: Early stages of scoliosis and spondylolisthesis entail changes in the intervertebral disc (IVD) structure and biochemistry. The current clinical use of MR T2-weighted images is limited to visual inspection. Our hypothesis is that the distribution of the MRI signal intensity within the IVD in T2-weighted images depends on the spinal pathology and on its severity. Therefore, this study aims to develop the AMRSID (analysis of MR signal intensity distribution) method to analyze the 3D distribution of the MR signal intensity within the IVD and to evaluate their sensitivity to scoliosis and spondylolisthesis and their severities.

Methods: This study was realized on 79 adolescents who underwent a MRI acquisition (sagittal T2-weighted images) before their orthopedic or surgical treatment. Five groups were considered: low severity scoliosis (Cobb angle $\leq 50^{\circ}$ ), high severity scoliosis (Cobb angles $>50^{\circ}$ ), low severity spondylolisthesis (Meyerding grades I and II), high severity spondylolisthesis (Meyerding grades III, IV and V) and control. The distribution of the MRI signal intensity within the IVD was analyzed using the descriptive statistics of histograms normalized by either cerebrospinal fluid or bone signal intensity, weighted centers and volume ratios. Differences between pathology and severity groups were assessed using one- and two-way ANOVAs.

Results: There were significant $(p<0.05)$ variations of indices between scoliosis, spondylolithesis and control groups and between low and high severity groups. The cerebrospinal fluid normalization was able to detect differences between healthy and pathologic IVDs whereas the bone normalization, which reflects both bone and IVD health, detected more differences between the severities of these pathologies.

Conclusions: This study proves for the first time that changes in the intervertebral disc, non visible to the naked eye on sagittal T2-weighted MR images of the spine, can be detected from specific indices describing the distribution of the MR signal intensity. Moreover, these indices are able to discriminate between scoliosis and spondylolisthesis and their severities, and provide essential information on the composition and structure of the discs whatever the pathology considered. The AMRSID method may have the potential to complement the current diagnostic tools available in clinics to improve the diagnostic with earlier biomarkers, the prognosis of evolution and the treatment options of scoliosis and spondylolisthesis.
\end{abstract}

Keywords: Intervertebral disc degeneration, MRI, Scoliosis, Spondylolisthesis, Histograms, Descriptive statistics

\footnotetext{
* Correspondence: delphine.perie@polymtl.ca

${ }^{1}$ Department of Mechanical Engineering, Ecole Polytechnique, Montreal,

Canada

${ }^{2}$ Research Center Sainte-Justine University Hospital, Montreal, Canada
}

\section{Biomed Central}

(c) 2012 Gervais et al.; licensee BioMed Central Ltd. This is an Open Access article distributed under the terms of the Creative Commons Attribution License (http://creativecommons.org/licenses/by/2.0), which permits unrestricted use, distribution, and reproduction in any medium, provided the original work is properly cited. 


\section{Background}

Spinal deformities such as scoliosis and spondylolisthesis affect both the structural and the biochemical composition of the intervertebral disc (IVD) [1,2] and lead to its degeneration. Adolescent Idiopathic Scoliosis (AIS) is marked by a wedging of the IVD linked with a displacement of the nucleus pulposus and changes in the glycosaminoglycan and water content repartition [3-6]. Spondylolisthesis is characterized by a loss of IVD height [7] and most of the time a disc degeneration [8]. Current radiologic measurements for AIS and spondylolisthesis are the Cobb angles and the Meyerding grades, respectively. However, they are 2D measurements of 3D spinal deformities and in addition they do not provide information on the biological and phenotypical aspects of the pathological discs.

Magnetic resonance imaging (MRI) can be a powerful tool for the diagnosis of spine pathologies. Diminished signal intensity in the IVD and evidence of radial tears in the annulus fibrosus (AF) were highly associated with positive symptoms on discography [9-18]. Changes in the intervertebral disc height, area or volume were quantified from MR images to highlight the effect of daily activities or various loading of the spine [19-22]. The displacements of the IVD components under various movements of the spine were also measured from MR images, highlighting significant correlations between the nucleus zone migration and the flexion-extension movements of the spine [23-25], or correlations between nucleus zone migration and intervertebral disc wedging in scoliosis $[6,26]$. Thus MRI can potentially help to monitor spine pathologies progression in vivo [27-29]. For instance, MRI gives reliable non-invasive 3D images of the IVD [30] allowing longitudinal follow-up studies in spine pathologies and T2-weighted images are used to assess the IVD degeneration [27,30,31]. Analysis of T2weighted images can help to detect early signs of disc degeneration $[4,32]$ but the current clinical use of T2weighted images is for the detection of late stages of the spine pathologies [30].

Recent studies further investigated MRI in the spine field with automated diagnosis. Disc herniation was evaluated with high precision of prediction (specificity 99\%, sensitivity 93\%) [33,34]. These studies were based on active shape modeling (2D), classifiers (2D) and histograms $(2 \mathrm{D} / 3 \mathrm{D})$, which were also used as research tools for automated diagnosis of other diseases such as liver metastases [35] or myocardial fibrosis by shape recognition and histogram analysis [36].

Our hypothesis is that the distribution of the MRI signal intensity within the IVD in T2-weighted images depends on the spinal pathology and on its severity, and consequently has the potential to provide essential information on spine pathologies that could not be appreciated by direct visual observation as currently performed in clinics [37]. Therefore, this study aims to develop new tools to analyze the 3D distribution of the MR signal intensity within the IVD and to evaluate their sensitivity to different spinal deformities (scoliosis or spondylolisthesis) and severities.

\section{Methods}

\section{Subjects' selection}

Seventy-nine subjects ( 32 with scoliosis, 32 with spondylolisthesis and 15 with herniated IVD) with an average age of 15.1 (range, 8-19.8) were selected from a clinical database of patient's images. The selected cases presented no other pathologies such as severe discopathies, herniation over the lumbar discs, no brace or surgical treatments prior to the MRI acquisition and/or no artifacts in the images. The subjects were divided into 5 groups: high severity scoliosis (Cobb Angle $50^{\circ}$ to $90^{\circ}, \mathrm{n}$ $=16$ ), low severity scoliosis (Cobb Angle $10^{\circ}$ to $49^{\circ}, \mathrm{n}=$ 16), high severity spondylolisthesis (Meyerding grade III to $\mathrm{V}, \mathrm{n}=16$ ), low severity spondylolisthesis (Meyerding grade I or II, $\mathrm{n}=16$ ) and controls (non-afflicted IVD from herniated patients, $n=15$ ). There were no significant differences in the distribution of the morphological parameters (Table 1) between each group, providing randomization. Each participating subject or in the case of minors, their legal guardian, gave informed consent for the use of their clinical data in future research projects. The research protocol was approved by the research ethics committee of our institutions. MR images (Figure 1) were all performed on the same $1.5 \mathrm{~T}$ system (Sonata, Siemens Healthcare, Erlangen, Germany) using a sagittal turbo spin echo T2-weighted sequence (slice thickness $3 \mathrm{~mm}$, gap $3.6 \mathrm{~mm}$, field of view of $350 * 350 \mathrm{~mm}$, matrix size of $512 * 512$, echo time of $121-$ $126 \mathrm{~ms}$ and repetition time of 3,200-3,690 ms).

\section{IVD selection and segmentation}

For the scoliosis groups, the disc under the apical vertebra of the lumbar curve was selected. For the spondylolisthesis groups, the L4/L5 IVD was selected, as high grades (IV and V) deformation of L5-S1 IVDs gives unreliable MR signal intensity. For the control group, the healthy IVD (L4/L5 or L2/L3) was selected. The segmentation was semi-automatically performed by a M.Sc. student in Biomedical Engineering using Slice-O-Matic (Tomovision, Magog (QC), Canada). This segmentation was realized for three zones (Figure 1): IVD, nucleus pulposus (NP) and annulus fibrosus (AF) and took about fifteen minutes per disc.

\section{Data normalisation}

Two-step normalization was done in order to minimize the discrepancy between the subjects and acquisition 
Table 1 Patient morphology and MRI scanning time of the day

\begin{tabular}{|c|c|c|c|c|c|}
\hline Patient & Mean & Median & Standard deviation & Min & Max \\
\hline Age (years) & 15.1 & 14.8 & 2.3 & 8.0 & 19.8 \\
\hline Height (cm) & 161.0 & 161.7 & 12.2 & 108.3 & 181.6 \\
\hline Weight (kg) & 56.3 & 56.8 & 13.4 & 18.3 & 99.2 \\
\hline Body Mass Index & 21.5 & 21.0 & 4.1 & 13.0 & 36.0 \\
\hline MRI acquisition time of the day & $12: 10$ & $13: 26$ & $1: 45$ & $7: 40$ & $18: 00$ \\
\hline
\end{tabular}

techniques (MatLab, Mathworks, Naticks (MA), USA). First, each voxel was set to a fraction of the IVD's volume to normalize the count of voxels between patients' histograms due to the variable disc sizes and image resolution between subjects. Then, MR intensity values were divided by normalizing intensities to minimize the variability due to variable patients' morphologies, variable MR acquisition gain and slightly variable TR and TE parameters. Two different normalizing intensities were used: the mean cerebrospinal fluid (CSF) intensity, which is known for its constant chemical composition and which is already used in the literature to normalize MR intensities [38-40], and the mean cancellous bone intensity of the above vertebra.

\section{Descriptive statistics of the MR intensities histogram}

The Gaussian distribution of the MR intensities histogram for the IVD, NP and AF was analyzed using the following indices: the standard deviation, the standard error, the median value, the sum of squared values, the $75^{\text {th }}$ percentile, the maximal voxel count in an intensity interval, the Skewness (index on the symmetry of the Gaussian distribution of the histogram) and the

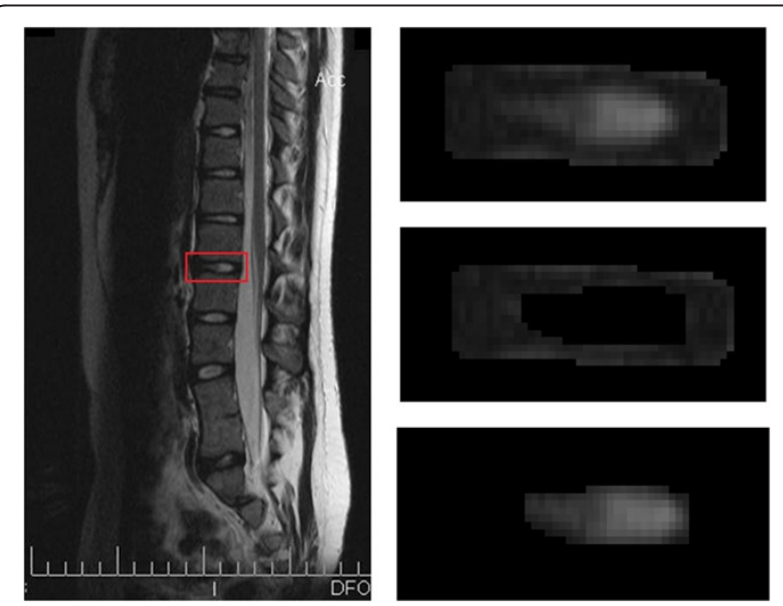

Figure 1 Segmentation process. An IVD is selected from a sagittal slice of the whole spine (Left). This IVD is then semi-automatically segmented into three parts: IVD (Top right), AF (middle right) and NP (bottom right).
Kolmogorov-Smirnov distance (maximum cumulative distance between the histogram distribution, and the Gaussian distribution of intensity data).

\section{Volume ratio between NP and full disc}

The volume ratio was computed as the ratio between the number of voxels within the segmented NP 3D matrix and the number of those within the segmented IVD 3D matrix as described by Violas et al. [41].

\section{Distance between weighted and geometrical centers}

The center of intensity (W) was adapted from Périé et al. [42]. It was defined as a tridimensional point which position was weighted by the MR intensity in each IVD, NP and AF zones (Figure 2) and calculated as follow:

$$
W(x, y, z)=\frac{\sum_{i=1}^{n} I_{i}\left(x_{i}, y_{i}, z_{i}\right) P_{i}\left(x_{i}, y_{i}, z_{i}\right)}{\sum_{i=1}^{n} I_{i}\left(x_{i}, y_{i}, z_{i}\right)}
$$

where $I$ is the MR signal intensity at the space position $\mathrm{P}$ described using $\mathrm{x}, \mathrm{y}$, and $\mathrm{z}$ coordinates in the local coordinate system of each disc and $n$ is the total number of points in the segmentation.

The normalized distance $(d)$ between the center of intensity $\mathrm{W}$ and the geometric center (G) of the IVD, which allows minimizing the effects of the variable IVD

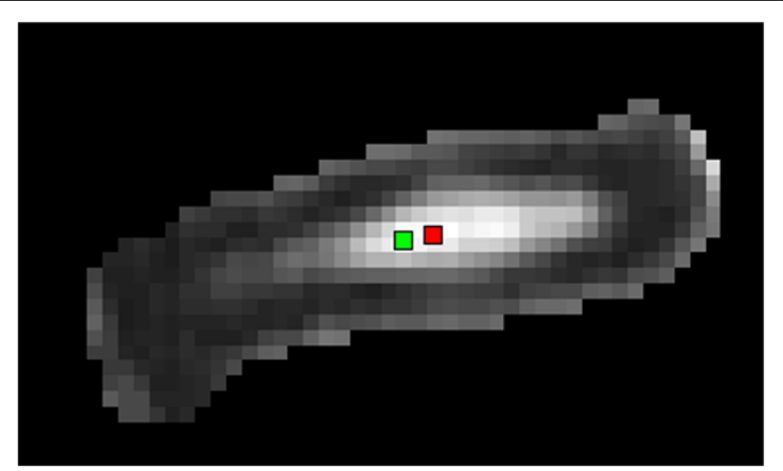

Figure 2 2D projection of the 3D distance between the geometric center (G) and the MRI intensity weighted center (W) in a spondylolisthesis patient's IVD. 
sizes and different local coordinate systems of each disc between subjects on the result, was calculated as follow:

$$
d=\frac{|\mathrm{W}(\mathrm{x}, \mathrm{y}, \mathrm{z})-\mathrm{G}(\mathrm{x}, \mathrm{y}, \mathrm{z})|}{\mathrm{N}}
$$

where $\mathrm{N}$ is the total number of voxels in the studied zone. This index represents an undirected translation in the IVD morphology from an ideally symmetric disc to a pathologic disc.

\section{Statistical analysis between groups}

Statistical analyses were performed using SIGMAPLOT 11.0 (Systat software Inc., San Jose, CA, USA). Differences between the scoliosis, spondylolisthesis and control groups were investigated using a one-way ANOVA for normally distributed, equal variance data. KruskalWallis ANOVA and Dunn's method of comparison were used for non-normal distributions. Differences between severity (low and high) and pathologic groups (Scoliosis and spondylolisthesis) were investigated using a two-way ANOVA for normally distributed, equal variance data. ANOVA on ranks with manual rank ordering was used for non-normal distributions. The distribution of the morphological parameters within the groups (Table 1) was unbiased and considered to have a negligible effect on the data.

\section{Results}

CSF normalized histograms of IVD

In the $\mathrm{AF}$, significant differences were found in the standard deviation, standard error, $75^{\text {th }}$ percentile and Kolmogorov-Smirnov distance between the control group and the groups with spinal deformity (Table 2). The Kolmogorov-Smirnov distance was significantly larger in low severity than in high severity groups. In the NP, significant differences were found in the standard deviation, standard error and Kolmogorov-Smirnov distance between control and scoliotic subjects. However, no significant differences were observed between the scoliosis and spondylisthesis groups. In the IVD, no significant differences were observed for all parameters between all groups, as illustrated by the similarity between the histograms (Figure 3a).

\section{Bone normalized histograms of the IVD}

In the AF, significant differences were found in the standard deviation, standard error, maximal voxel count in an intensity interval, median, $75^{\text {th }}$ percentile and Kolmogorov-Smirnov distance between the control and the groups with spinal deformity (Table 2). Significant differences were also noted in the skewness between the severity groups. In the NP, significant differences were observed in the Kolmogorov-Smirnov distance between

Table 2 Significant differences found on the descriptive statistics of the histogram between pathology and severity groups

$\begin{array}{llllll}\begin{array}{l}\text { Region of } \\ \text { interest }\end{array} & \begin{array}{l}\text { Standard } \\ \text { deviation }\end{array} & \begin{array}{l}\text { Standard } \\ \text { error }\end{array} & \begin{array}{l}\text { Kolmogorov-Smirnov } \\ \text { distance }\end{array} & \begin{array}{l}75^{\text {th }} \\ \text { percentile }\end{array} & \begin{array}{l}\text { Median } \\ \begin{array}{l}\text { Maximal voxel } \\ \text { count in an } \\ \text { intensity interval }\end{array}\end{array} \begin{array}{l}\text { Sum of } \\ \text { squared } \\ \text { values }\end{array}\end{array}$

\begin{tabular}{|c|c|c|c|c|c|c|c|c|c|}
\hline \multicolumn{10}{|c|}{ Control/Scoliosis } \\
\hline \multirow{2}{*}{$\begin{array}{l}\text { CSF } \\
\text { normalization }\end{array}$} & AF & $* *$ & $* *$ & $* *$ & $* *$ & & $* *$ & & \\
\hline & NP & $*$ & * & $* *$ & & & & & \\
\hline \multirow{2}{*}{$\begin{array}{l}\text { Bone } \\
\text { normalization }\end{array}$} & $\mathrm{AF}$ & $*$ & $*$ & ** & $* *$ & $* *$ & $* *$ & & \\
\hline & NP & & & $*$ & & & & & \\
\hline \multicolumn{10}{|c|}{ Control/Spondylolisthesis } \\
\hline $\begin{array}{l}\text { CSF } \\
\text { normalization }\end{array}$ & $\mathrm{AF}$ & $* *$ & $* *$ & $* *$ & $* *$ & & $* *$ & & \\
\hline $\begin{array}{l}\text { Bone } \\
\text { normalization }\end{array}$ & $\mathrm{AF}$ & $*$ & * & $* *$ & $* *$ & $* *$ & $* *$ & & \\
\hline \multicolumn{10}{|c|}{ Scoliosis/Spondylolisthesis } \\
\hline $\begin{array}{l}\text { Bone } \\
\text { normalization }\end{array}$ & IVD & & & $*$ & & & & & \\
\hline \multicolumn{10}{|c|}{ Severity low/high } \\
\hline $\begin{array}{l}\text { CSF } \\
\text { normalization }\end{array}$ & $\mathrm{AF}$ & & & $*$ & & & & & \\
\hline \multirow{2}{*}{$\begin{array}{l}\text { Bone } \\
\text { normalization }\end{array}$} & IVD & $*$ & $*$ & & & & & * & * \\
\hline & $A F$ & & & & & & & & * \\
\hline
\end{tabular}

Results were considered significant $(*)$ for $p<0.05$ and highly significant $\left.{ }^{* *}\right)$ for $p \leq 0.001$. 

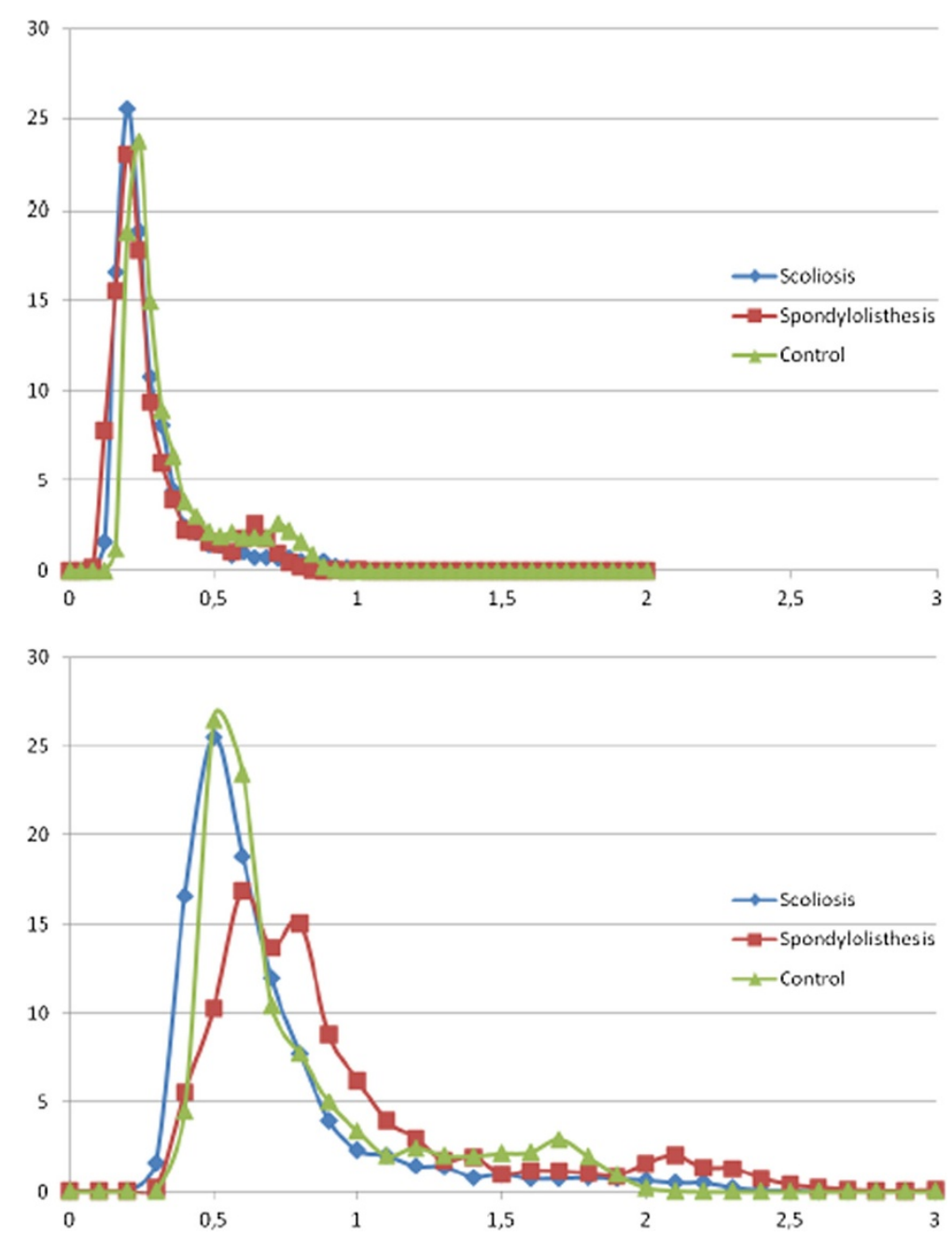

Figure 3 Comparative MRI signal intensity histogram in the IVD between pathologies from normalized data using the average value of the CSF intensity (a) and the average value of the cancellous bone (b). The $x$ axis represents the gray level and the $Y$ axis the number of pixels.

the control and the scoliotic groups. Similarly, in the IVD, the Kolmogorov-Smirnov distance was significantly higher for scoliosis than spondylolisthesis subjects, as illustrated by a different histogram shape for spondylolisthesis than for scoliosis or control (Figure 3b). Significant differences were also found in the standard deviation, standard error, skewness and sum of squared values between severity groups.

\section{Mean bone and CSF intensities}

The mean bone intensity was not influenced by neither the pathology $(\mathrm{p}=0.19)$ nor the severity $(\mathrm{p}=0.72)$. On the contrary, the mean CSF intensity was highly influenced by both the pathology $(\mathrm{p}=0.02)$ and the severity $(p=0.04)$. The CSF being constant between subjects, these signal changes are only due to the gain of the MR system between acquisitions. Thus the gain of the MR system is influenced by both the pathology and the severity. However, the ratio of the bone mean intensity divided by the CSF mean intensity was not linked to the pathology $(\mathrm{p}=0.42)$ nor its severity $(\mathrm{p}=0.1)$. The coupled effect of the MR system gain and vertebral bone changes are not influenced by the pathology nor its severity.

\section{Volume ratio between NP and full disc}

A significant decrease was observed between control and pathologic groups ( $\mathrm{p} \leq 0.001$, Table 3 ). However, no significant differences were observed between the scoliosis and the spondylisthesis groups, and between the severity groups.

\section{Distance between weighted and geometrical centers}

In the AF, NP and IVD, a significant increase of $50 \%$ (Table 4) was found ( $\leq \leq 0.001$, Table 5) between the control and the scoliosis groups. Highly significant 
Table 3 Volume ratio (\%) between the NP and IVD for each pathology and severity group

\begin{tabular}{llll}
\hline Group & Severity & Mean value & Standard deviation \\
\hline Scoliosis & Low & $18.9 \%$ & $3.4 \%$ \\
& High & $19.9 \%$ & $5.0 \%$ \\
Spondylolisthesis & Low & $22.2 \%$ & $3.6 \%$ \\
& High & $18.0 \%$ & $4.8 \%$ \\
Control & & $27.0 \%$ & $6.3 \%$ \\
\hline
\end{tabular}

differences were also detected ( $\mathrm{p} \leq 0.001$, Table 5) between the scoliosis and the spondylolisthesis groups. Similarly, significant differences was found $(\mathrm{p}=0.05$, Table 5) between severity groups in the NP zone. However, no significant differences were found between the control and the spondylolisthesis groups in any zone.

\section{Discussion}

The histograms of MR intensities within the intervertebral discs were analysed for the first time using descriptive statistics. Our hypothesis was validated as the results revealed a variation of the MR signal intensity within T2-weighted images of IVDs, which was different between spine pathologies and their severities. The AMRSID method and the new parameters proposed to analyse the MR signal within the IVD has the potential to provide essential information on spine pathologies

\section{Table 4 Normalized distance between weighted and geometrical centers for each pathology and severity group}

\begin{tabular}{llll}
\hline Pathology & Severity & Mean value & Std \\
\hline IVD & & & \\
Scoliosis & Low & 0.50 & 0.28 \\
& High & 0.50 & 0.17 \\
Spondylolisthesis & Low & 0.12 & 0.09 \\
& High & 0.16 & 0.10 \\
Control & & 0.22 & 0.11 \\
AF & & & \\
Scoliosis & Low & 0.52 & 0.28 \\
& High & 0.50 & 0.22 \\
Spondylolisthesis & Low & 0.28 & 0.12 \\
& High & 0.35 & 0.28 \\
Control & & 0.20 & 0.06 \\
NP & & & \\
Scoliosis & Low & 1.86 & 1.43 \\
& High & 2.01 & 1.12 \\
Spondylolisthesis & Low & 0.80 & 0.56 \\
& High & 1.41 & 0.91 \\
Control & & 0.95 & 0.52 \\
\hline
\end{tabular}

that could not be appreciated by direct visual observation as currently performed in clinical routine.

\section{Descriptive statistics of normalized histograms}

The results highlighted the following links between MR signal intensity and morphologic variations of the IVD. The standard deviation represents the width of the Gaussian peak and rises with increasing severity, which represented a decrease for the transition sharpness between the AF and NP, and morphologically the degeneration of the inner AF and NP. The sum of square showed the loss of the high white intensities values within the IVD and rose with increasing severity, which represented the loss of the healthy NP and inner-AF and thus was likely to reflect their degeneration. The Skewness detected the loss of inner AF intensities and rose with increasing severity, which represented the structural degeneration of the AF. The KolmogorovSmirnov distance detected the original slope of the curve as well as the loss of high AF and IVD intensities. It was greater for scoliotic than for spondylolisthesis patients and decreases with increasing severity. It gave essential information on the structural degeneration of the IVD with a loss of the original morphologic equilibrium. The maximum, the median and the $75^{\text {th }}$ percentile likely illustrated the homogeneity of the IVD tissues given by the concentration of the total MR intensity data around a few number of intensities. The more homogeneous the IVD, the more degenerated it was. This degeneration reflected a loss of the collagen matrix integrity in the NP and a diffusion of the molecules such as proteoglycans, leading to a loss of osmotic pressure and of disc hydration. The standard error represented the variation of the mean value between the perfect Gaussian and the obtained distribution and rose with increasing severities, which represented a decrease of the IVD's hydration on T2-weighted images.

\section{Volume ratio and weighted center}

The results were consistent with those in the literature with a mean volume ratio equal to $24 \%$ for scoliotic discs [41]. This index was found higher for control than for pathologic groups, which was expected since it detected the loss of the NP volume within the pathologic discs. The distance between the weighted and geometrical centers was only analysed in $2 \mathrm{D}$ by Perie et al. $[6,26,42]$. Our 3D index, which showed significant differences due to the pathology and severity, related the geometric intensity distribution variations and thus expressed structural and composition changes in the IVD, AF and NP. It detected the asymmetry in the IVD and described the tridimensional geometry of the disc degeneration. A clinical longitudinal follow-up of these indices would lead to a better understanding of the 
Table 5 Significant differences on the distance between weighted and geometrical centers and on the volume ratio between pathology and severity groups

\begin{tabular}{|c|c|c|}
\hline & Region of interest & Significance \\
\hline \multicolumn{3}{|l|}{ Control vs. Scoliosis } \\
\hline \multirow[t]{3}{*}{ Distance between weighted and geometrical centers } & IVD & $* *$ \\
\hline & $\mathrm{AF}$ & $* *$ \\
\hline & NP & $* *$ \\
\hline Volume Ratio & & $* *$ \\
\hline \multicolumn{3}{|l|}{ Control vs. Spondylolisthesis } \\
\hline Volume Ratio & & $* *$ \\
\hline \multicolumn{3}{|l|}{ Scoliosis vs. Spondylolisthesis } \\
\hline \multirow[t]{3}{*}{ Distance between weighted and geometrical centers } & IVD & $* *$ \\
\hline & $\mathrm{AF}$ & $* *$ \\
\hline & NP & $* *$ \\
\hline \multicolumn{3}{|l|}{ Severity Low vs. High } \\
\hline Distance between weighted and geometrical centers & NP & * \\
\hline
\end{tabular}

Results were considered significant $(*)$ for $p<0.05$ and highly significant $\left({ }^{*}\right)$ for $p \leq 0.001$.

various IVD degeneration processes caused by spinal deformities. It is believed to have potential in providing critical information on the evolution of the spinal pathologies, and of the treatment.

\section{Bone and CSF normalizations}

Normalizations were based on CSF and bone tissues MR signal intensity. Because of its constant composition between patients, the CSF normalization suppresses the acquisition gain from the signal intensity. Because bone tissues are known to remodel with spine pathologies $[43,44]$, the bone normalization evaluated bone health and suppressed the acquisition gain at the same time. Based on the highly significant differences between groups from this study, we concluded that CSF normalization was able to detect differences between healthy and pathologic IVD whereas bone normalization detected more differences between the severities of these pathologies. The bone normalization was able to reflect both the bone and IVD health. This particularity allowed finding differences between the two severity groups.

\section{Limitations of the study}

Each patient group was created to separate the surgical cases from the non-surgical cases. However, the distribution of age, height, weight, body mass index and MRI acquisition time of the patients in each group was heterogeneous. Such parameters are known to influence the MR signal intensity because of physiologic variations during growth peak and diurnal changes within the IVD $[38,45]$. As no significant differences in the distribution of these parameters were found between each group, the randomization was assumed and their effect was neglected.
The control cases are not from normal subjects but from patients with a herniated IVD. Because the biomechanical forces that are responsible in the pathophysiology of the IVD disease are usually exerting their effect over several levels, we chose a healthy disc three levels away from the herniated IVD, and we verified with a radiologist that the chosen IVD did not have abnormal MR signal distribution.

Segmentations of the IVD, NP and AF zones were processed semi-automatically, including the user's perception. Thus we studied the sensitivity of the method to the segmentation process and data normalization [46]. The repetition of the semi-automatic segmentation by a same operator did not influence the quality of the contour or our new MR distribution parameters while the skills of the operator influenced only the MR distribution parameters. The instructions given prior to the segmentation influenced both the quality of the contour and the MR distribution parameters. Bone normalization produces an index which jointly highlights IVD and bone health, whereas CSF normalization only suppresses the effect of the acquisition gain. Segmentations used in this study provided reliable analysis results.

The segmentation is the longest process in our data analysis as it requires a manual intervention of the operator and takes about fifteen minutes per disc. An automatic process would decrease drastically this segmentation time. Some attempts to perform automatic segmentation of the IVD were proposed on T1-weighted images $[47,48]$, but not for T2-weighted images in which there is not enough contrast between bone and annulus fibrosus.

MRI studies are realized in supine position and not in standing posture. However, our team demonstrated that 
the MR parameters of IVDs are not sensitive to compression (up to $40 \%$ deformation) neither to the partial confined relaxation that followed the compression [49].

\section{Clinical applications}

$\mathrm{X}$-ray films do not allow the analysis of the IVD, except its height that shows late stages of degeneration. The AMRSID method showed promising results that suggested the potential to change the prognosis or treatment options of scoliosis and spondylolisthesis. In AIS, the quantitative analysis of the apical disc may help predict curve progression in primary or secondary curves by indicating the level of IVD abnormalities and degeneration. However, no study has already correlated the IVD changes to the prognosis or the rate of progression of the AIS. To that end, longitudinal follow-up studies associated to the AMRSID method are necessary, in which the comparison of the MR signal distribution patterns will allow the definition of predictive factors of scoliosis progression using contingency tables, relative risk and percentage attributable risk factors. In L5-S1 spondylolisthesis, the AMRSID method may help surgical decision making by revealing evidence of disc degeneration above the affected level, and help surgeons to decide if this adjacent level should or should not be included in the fusion. Consequently, the clinical practice could be modified by the inclusion of a MRI acquisition associated to the AMRSID method for the diagnosis. Moreover, the treatment planning could be monitored in part by the results of the AMRSID method.

The application of the AMRSID method to elderly subjects needs to consider the IVD aging as a factor influencing the MR signal. Thus, a similar study has to be performed to verify that the distribution of the MRI signal intensity within the IVD in T2-weighted images depends on the spinal pathology, its severity and the aging degradation.

Images with enhanced resolution could lead to the discovery of more significant indices describing scoliosis and spondylolisthesis. Moreover, multi-parametric MRI is known to provide information on mechanical, structural and biochemical properties of the IVD [50-53] and could lead to new indices reflecting more aspects of the changes induced in the IVD by spine pathologies. Proton MR-spectroscopy, which evaluates the relative concentration of metabolites in tissues, might be used to assess IVD degeneration and proteoglycan content $[54,55]$.

\section{Conclusions}

This study proves for the first time that changes in the intervertebral disc, non appreciated by direct visual observation as currently performed in clinical routine, can be detected from specific indices describing the distribution of the signal intensity on sagittal T2weighted MR images of the spine. Moreover, these indices are able to discriminate between the spinal deformities and their severities, and provide essential information on the composition and structure of the discs whatever the spine deformity considered. The AMRSID method has the potential to complement the current diagnostic tools available in clinics to improve the diagnostic with earlier biomarkers, the prognosis of evolution and the treatment options of scoliosis and spondylolisthesis. However, before being used in clinics, the resolution of the MR images has to be increased during the acquisition or during the post-treatment, an automatic segmentation process of the IVD has to be developed to reduce the data treatment duration, and longitudinal studies have to be performed to investigate the relationship between the IVD degenerescence and the evolution of scoliosis and spondylolisthesis.

\section{Competing interests}

The authors declare that they have no competing interests.

\section{Authors' contributions}

JG carried out the developments, all the data analysis, discussed the results and drafted the manuscript. CE, SP and HL participated to the results discussion and corrected the manuscript. DP proposed the design of the study, participated to the results discussion and the draft of the manuscript, and made the revisions of the manuscript. All authors read and approved the final manuscript.

\section{Acknowledgment}

The authors would like to thank Dr Marie-Claude Miron, Dr Gilles Beaudoin, Dr Sylvain Deschénes, Mohamed Aissiou, Kessen Patten and Julie Joncas for their contribution to this study.

Funded by grants from the Natural Sciences and Engineering Research Council (NSERC) of Canada, the Foundation of Stars and the Foundation CHU Sainte-Justine, the Groupe de Recherche en Sciences et Technologies Biomédicales (GRSTB), the Fonds de Recherche en Santé du Québec (FRSQ), the Foundation of École Polytechnique and the Scoliosis Research Society.

Received: 24 May 2012 Accepted: 19 November 2012 Published: 3 December 2012

\section{References}

1. Bushell GR, Ghosh P, Taylor TK, Sutherland JM: The collagen of the intervertebral disc in adolescent idiopathic scoliosis. J Bone Joint Surg Br 1979, 61-B:501-508.

2. Antoniou J, Arlet V, Goswami T, Aebi M, Alini M: Elevated synthetic activity in the convex side of scoliotic intervertebral discs and endplates compared with normal tissues. Spine (Phila Pa 1976) 2001, 26:E198-206.

3. Urban MR, Fairbank JCT, Bibby SRS, Urban JPG: Intervertebral disc composition in neuromuscular scoliosis - changes in cell density and glycosaminoglycan concentration at the curve apex. Spine 2001, 26:610-617.

4. Schlenzka D, Poussa M, Seitsalo S, Osterman K: Intervertebral disc changes in adolescents with isthmic spondylolisthesis. J Spinal Disord 1991, 4:344-352.

5. Kouwenhoven JWM, Castelein RM: The pathogenesis of adolescent idiopathic scoliosis review of the literature. Spine 2008, 33:2898-2908.

6. Perie D, Sales de Gauzy J, Curnier D, Hobatho MC: Intervertebral disc modeling using a MRI method: migration of the nucleus zone within scoliotic intervertebral discs. Magn Reson Imaging 2001, 19:1245-1248.

7. Chen IR, Wei TS: Disc height and lumbar index as independent predictors of degenerative spondylolisthesis in middle-aged women with low back pain. Spine (Phila Pa 1976) 2009, 34:1402-1409. 
8. Dai LY: Disc degeneration in patients with lumbar spondylolysis. J Spinal Disord 2000, 13:478-486.

9. Horton WC, Daftari TK: Which disc as visualized by magnetic resonance imaging is actually a source of pain? A correlation between magnetic resonance imaging and discography. Spine (Phila Pa 1976) 1992, 17:S164-S171.

10. Kornberg M: Discography and magnetic resonance imaging in the diagnosis of lumbar disc disruption. Spine (Phila Pa 1976) 1989, 14:1368-1372.

11. Linson $\mathrm{MA}$, Crowe $\mathrm{CH}$ : Comparison of magnetic resonance imaging and lumbar discography in the diagnosis of disc degeneration. Clin Orthop Relat Res 1990, 250:160-163.

12. Osti OL, Fraser RD: MRI and discography of annular tears and intervertebral disc degeneration. A prospective clinical comparison. J Bone Joint Surg Br 1992, 74:431-435.

13. Schneiderman G, Flannigan B, Kingston S, Thomas J, Dillin WH, Watkins RG: Magnetic resonance imaging in the diagnosis of disc degeneration: correlation with discography. Spine (Phila Pa 1976) 1987, 12:276-281.

14. Aprill C, Bogduk N: High-intensity zone: a diagnostic sign of painful lumbar disc on magnetic resonance imaging. Br J Radiol 1992, 65:361-369.

15. Ross JS, Modic MT, Masaryk TJ: Tears of the anulus fibrosus: assessment with Gd-DTPA-enhanced MR imaging. AJNR Am J Neuroradiol 1989, 10:1251-1254

16. Sether LA, Yu S, Haughton VM, Fischer ME: Intervertebral disk: normal agerelated changes in MR signal intensity. Radiology 1990, 177:385-388.

17. Yu SW, Haughton VM, Sether LA, Wagner M: Anulus fibrosus in bulging intervertebral disks. Radiology 1988, 169:761-763.

18. Schmidt TA, An HS, Lim TH, Nowicki BH, Haughton VM: The stiffness of lumbar spinal motion segments with a high-intensity zone in the anulus fibrosus. Spine (Phila Pa 1976) 1998, 23:2167-2173.

19. Boos N, Wallin A, Gbedegbegnon T, Aebi M, Boesch C: Quantitative MR imaging of lumbar intervertebral disks and vertebral bodies: influence of diurnal water content variations. Radiology 1993, 188:351-354.

20. Malko JA, Hutton WC, Fajman WA: An in vivo magnetic resonance imaging study of changes in the volume (and fluid content) of the lumbar intervertebral discs during a simulated diurnal load cycle. Spine (Phila Pa 1976) 1999, 24:1015-1022.

21. LeBlanc AD, Evans HJ, Schneider VS, Wendt RE 3rd, Hedrick TD: Changes in intervertebral disc cross-sectional area with bed rest and space flight. Spine (Phila Pa 1976) 1994, 19:812-817.

22. Hedman TP, Fernie GR: In vivo measurement of lumbar spinal creep in two seated postures using magnetic resonance imaging. Spine (Phila Pa 1976) 1995, 20:178-183.

23. Beattie PF, Brooks WM, Rothstein JM, Sibbitt WL Jr, Robergs RA, MacLean T, Hart BL: Effect of lordosis on the position of the nucleus pulposus in supine subjects. A study using magnetic resonance imaging. Spine (Phila Pa 1976) 1994, 19:2096-2102

24. Fennell AJ, Jones AP, Hukins DW: Migration of the nucleus pulposus within the intervertebral disc during flexion and extension of the spine. Spine (Phila Pa 1976) 1996, 21:2753-2757.

25. Brault JS, Driscoll DM, Laakso LL, Kappler RE, Allin EF, Glonek T: Quantification of lumbar intradiscal deformation during flexion and extension, by mathematical analysis of magnetic resonance imaging pixel intensity profiles. Spine (Phila Pa 1976) 1997, 22:2066-2072.

26. Perie D, Curnier D, de Gauzy JS: Correlation between nucleus zone migration within scoliotic intervertebral discs and mechanical properties distribution within scoliotic vertebrae. Magn Reson Imaging 2003, 21:949-953.

27. Majumdar S: Magnetic resonance imaging and spectroscopy of the intervertebral disc. NMR Biomed 2006, 19:894-904

28. Endean A, Palmer KT, Coggon D: Potential of Magnetic Resonance Imaging Findings to Refine Case Definition for Mechanical Low Back Pain in Epidemiological Studies: A Systematic Review. Spine (Phila Pa 1976) 2011, 36:160-169.

29. Mwale F, latridis JC, Antoniou J: Quantitative MRI as a diagnostic tool of intervertebral disc matrix composition and integrity. Eur Spine J 2008, 17(Suppl 4):432-440

30. Pfirrmann CW, Metzdorf A, Zanetti M, Hodler J, Boos N: Magnetic resonance classification of lumbar intervertebral disc degeneration. Spine (Phila Pa 1976) 2001, 26:1873-1878.
31. Antoniou J, Pike GB, Steffen T, Baramki H, Poole AR, Aebi M, Alini M: Quantitative magnetic resonance imaging in the assessment of degenerative disc disease. Magn Reson Med 1998, 40:900-907.

32. Wang C, Auerbach JD, Witschey WR, Balderston RA, Reddy R, Borthakur A: Advances in magnetic resonance imaging for the assessment of degenerative disc disease of the lumbar spine. Semin Spine Surg 2007, 19:65-71.

33. Alomari RS, Corso JJ, Chaudhary V, Dhillon G: Automatic Diagnosis of Lumbar Disc Herniation with Shape and Appearance Features from MRI In Medical Imaging 2010: Computer-Aided Diagnosis, 16-18 Feb 2010. USA: SPIE - The International Society for Optical Engineering; 2010:76249. 76241A.

34. Koh J, Chaudhary V, Dhillon G: Diagnosis of Disc Herniation Based on Classifiers and Features Generated from Spine MR Images. In Medical Imaging 2010: Computer-Aided Diagnosis, 16-18 Feb 2010. USA: SPIE - The International Society for Optical Engineering; 2010:76248. 76243O.

35. Positano V, Brotini L, Aquaro G, Pingitore A, Lombardi M, Landini L, Santarelli MF: Automatic assessment of myocardial fibrosis by delayed enhanced magnetic resonance imaging. In Piscataway, NJ, USA. IEEE International Symposium on Biomedical Imaging: From Macro to Nano. 2008:1497-1500

36. Freiman $M$, Edrei $Y$, Gross $E$, Joskowicz $L$, Abramovitch R: Liver metastasis early detection using fMRI based statistical model. Piscataway: IEEE; 2008:584-587.

37. Patriarche J, Erickson B: Part 2. Automated change detection and characterization applied to serial MR of brain tumors may detect progression earlier than human experts. J Digit Imaging 2007, 20:321-328.

38. Kerttula L, Kurunlahti M, Jauhiainen J, Koivula A, Oikarinen J, Tervonen O: Apparent diffusion coefficients and $\mathrm{T} 2$ relaxation time measurements to evaluate disc degeneration. A quantitative MR study of young patients with previous vertebral fracture. Acta Radiol 2001, 42:585-591.

39. Kerttula LI, Serlo WS, Tervonen OA, Paakko EL, Vanharanta HV: Posttraumatic findings of the spine after earlier vertebral fracture in young patients: clinical and MRI study. Spine (Phila Pa 1976) 2000, 25:1104-1108

40. Luoma K, Vehmas T, Grönblad M, Kerttula L, Kääpä E: MRI follow-up of subchondral signal abnormalities in a selected group of chronic low back pain patients. Eur Spine J 2008, 17:1300-1308.

41. Violas P, Estivalezes E, Briot J, Sales de Gauzy J, Swider P: Quantification of intervertebral disc volume properties below spine fusion, using magnetic resonance imaging, in adolescent idiopathic scoliosis surgery Spine 2007, 32:E405-412.

42. Perie D, Curnier D: Effect of pathology type and severity on the distribution of MRI signal intensities within the degenerated nucleus pulposus: application to idiopathic scoliosis and spondylolisthesis. BMC Musculoskelet Disord 2010, 11:189.

43. Perie D, Sales De Gauzy J, Baunin C, Hobatho MC: Tomodensitometry measurements for in vivo quantification of mechanical properties of scoliotic vertebrae. Clin Biomech (Bristol, Avon) 2001, 16:373-379.

44. Perie D, Hobatho MC, Baunin C, Sales De Gauzy J: Personalised mechanical properties of scoliotic vertebrae determined in vivo using tomodensitometry. Comput Methods Biomech Biomed Engin 2002, 5:161-165.

45. Ludescher B, Effelsberg J, Martirosian P, Steidle G, Markert B, Claussen C, Schick F: T2- and diffusion-maps reveal diurnal changes of intervertebral disc composition: an in vivo MRI study at 1.5 Tesla. J Magn Reson Imaging 2008, 28:252-257

46. Gervais J, Perie D, Aubin C: Sensitivity of MRI signal distribution within the intervertebral disc to image segmentation and data normalization. Comput Methods Biomech Biomed Engin 2012, In press.

47. Chevrefils C, Cheriet F, Aubin CE, Grimard G: Texture analysis for automatic segmentation of intervertebral disks of scoliotic spines from MR images. IEEE Trans Inf Technol Biomed 2009, 13:608-620.

48. Michopoulou SK, Costaridou L, Panagiotopoulos E, Speller R, Panayiotakis G, Todd-Pokropek A: Atlas-based segmentation of degenerated lumbar intervertebral discs from MR images of the spine. IEEE Trans Biomed Eng 2009, 56:2225-2231

49. Manac'h YG, Perie D, Gilbert G, Beaudoin G: Sensitivity of multi-parametric MRI to the compressive state of the isolated intervertebral discs. Magn Reson Imaging 2012, In press.

50. Boos N, Boesch C: Quantitative magnetic-resonance-imaging of the lumbar spine - potential for investigations of water-content and biochemical-composition. Spine 1995, 20:2358-2365. 
51. Benneker LM, Heini PF, Anderson SE, Alini M, Ito K: Correlation of radiographic and MRI parameters to morphological and biochemical assessment of intervertebral disc degeneration. Eur Spine J 2005, 14:27-35.

52. O'Connell GD, Johannessen W, Vresilovic EJ, Elliott DM: Human internal disc strains in axial compression measured noninvasively using magnetic resonance imaging. Spine 2007, 32:2860-2868.

53. Nguyen AM, Johannessen W, Yoder JH, Wheaton AJ, Vresilovic EJ, Borthakur A, Elliott DM: Noninvasive quantification of human nucleus pulposus pressure with use of T1rho-weighted magnetic resonance imaging. J Bone Joint Surg Am 2008, 90:796-802.

54. Zuo J, Saadat E, Romero A, Loo K, Li X, Link TM, Kurhanewicz J, Majumdar S: Assessment of intervertebral disc degeneration with magnetic resonance single-voxel spectroscopy. Magn Reson Med 2009, 62:1140-1146.

55. Zuo J, Joseph GB, Li X, Link TM, Hu SS, Berven SH, Kurhanewitz J, Majumdar $S$ : In vivo intervertebral disc characterization using magnetic resonance spectroscopy and T1rho imaging: association with discography and Oswestry Disability Index and Short Form-36 Health Survey. Spine (Phila Pa 1976) 2012, 37:214-221.

doi:10.1186/1471-2474-13-239

Cite this article as: Gervais et al:: MRI signal distribution within the intervertebral disc as a biomarker of adolescent idiopathic scoliosis and spondylolisthesis. BMC Musculoskeletal Disorders 2012 13:239.

\section{Submit your next manuscript to BioMed Central and take full advantage of:}

- Convenient online submission

- Thorough peer review

- No space constraints or color figure charges

- Immediate publication on acceptance

- Inclusion in PubMed, CAS, Scopus and Google Scholar

- Research which is freely available for redistribution 